\title{
PENGEMBANGAN MEDIA PEMBELAJARAN INTERAKTIF BERBASIS ADOBE FLASH CS6 PADA MATA PELAJARAN DASAR DESAIN GRAFIS KELAS X MULTIMEDIA SMK ISLAM AL AMIN BONANG DEMAK
}

\author{
Indana Zulfa \\ SMK Islam Al Amin Bonang Demak \\ Email: zindana738@gmail.com \\ Diterima: April 2019. Disetujui: Mei 2019. Dipublikasikan: Juni 2019
}

\begin{abstract}
ABSTRAK
Kurangnya media pembelajaran dalam proses pembelajaran di SMK Islam Al amin khususnya pada mata pelajaran dasar desain grafis yang hanya bersumber dari buku, dan internet. Penelitian ini bertujuan untuk : (1) Untuk merancang pengembangan media pembelajaran interaktif berbasis adobe flash CS6 (2) Mengimplementasikan media pembelajaran interaktif berbasis adobe flash CS6 (3) Untuk menguji kelayakan media pembelajaran interaktif berbasis adobe flash CS6. Penelitian ini menggunakan metode penelitian (Research and Davelopment) dengan model yang terdiri dari tiga tahapan prosedur pengembangan, yaitu (1) analisis kebutuhan, (2) desain, (3) pengembangan dan implementasi. Subjek penelitian adalah 20 siswa jurusan Multimedia kelas X SMK Islam Al amin Bonang Demak. Objek penelitian adalah media pembelajaran interaktif. Instrumen penelitian yang digunakan berupa angket modifikasi skala likert dengan lima pilihan jawaban yang digunakan untuk memperoleh data tingkat kelayakan media pembelajaran. Hasil menunjukkan bahwa: (1) Media pembelajaran interaktif pada mata pelajaran dasar desain grafis dapat menjadi variasi media untuk pembelajaran, (2) media pembelajaran interaktif pada mata pelajaran dasar desain grafis terdiri dari materi dasar desain grafis, animasi tampilan, video tutorial, dan kuis pilihan ganda, (3) tingkat kelayakan media pembelajaran ditinjau dari: (a) aspek media dinyatakan "Layak" oleh ahli media dengan persentase $69 \%$. (b) aspek materi dinyatakan "Sangat Layak" oleh ahli materi dengan persentase 94,5\%. (c) penilaian pengguna atau siswa memperoleh persentase sebesar 90\% dengan kategori "Sangat Layak".
\end{abstract}

Kata kunci: media pembelajaran interaktif, dasar desain grafis , adobe flash CS6

\begin{abstract}
The lack of learning media in the learning process in Al Amin Islamic Vocational School, especially in the basic subjects of graphic design that only comes from books, and the internet. This study aims to: (1) To design the development of interactive learning media based on adobe flash CS6 (2) Implement interactive learning media based on adobe flash CS6 (3) To test the feasibility of interactive learning media based on adobe flash CS6. This study uses research (Davelopment) method with a model consisting of three stages of development procedures, namely (1) needs analysis, (2) design, (3) development and implementation. The research subjects were 20 Multimedia students in class X Al Amin Bonang Islamic Vocational School Demak. The object of research is interactive learning media. The research instrument used was a Likert scale modification questionnaire with five answer choices that were used to obtain data on the level of feasibility of learning media. The results show that: (1) Interactive learning media on basic graphic design subjects can be a variety of media for learning, (2) interactive learning media on basic graphic design subjects consisting of basic graphic design material, display animation, video tutorials, and quizzes multiple choice, (3) the level of feasibility of learning media in terms of: (a) the aspect of the media declared "Eligible" by media experts with a percentage of 69\%. (b) material aspects are declared "Very Worthy" by material experts with a percentage of $94.5 \%$. (c) the assessment of users or students gets a percentage of $90 \%$ with the category "Very Worthy". Keywords: interactive learning media, basic graphic design, adobe flash CS6
\end{abstract}




\section{PENDAHULUAN}

Perkembangan

teknologi

memberikan dampak dan pengaruh pada kehidupan manusia, termasuk juga pada dunia pendidikan di dalamnya. Karena tidak menutup kemungkinan bahwa dalam dunia pendidikan sekarang ini tidak lepas dari penggunaan media elektronik berupa komputer. Sebuah komputer merupakan suatu kesatuan sistem yang terdiri atas perangkat keras dan lunak. Baik perangkat keras maupun perangkat lunak, para produsennya terus melakukan pengembangan mencapai kesempurnaan produk. Pengembangannya dilakukan baik dari segi dimensi, kecepatan prosesor, sistem operasi dan lain sebagainya. Untuk saat ini penggunaan komputer untuk pembelajaran telah banyak digunakan, baik pada tingkat sekolah dasar hingga tingkat perguruan tinggi.

Sekolah Menengah Kejuruan (SMK) adalah salah satu dari beberapa bentuk pendidikan menengah kejuruan, dimana pendidikan menengah kejuruan menyiapkan para siswanya untuk siap bekerja dalam bidang tertentu sesuai dengan program keahliannya. Perkembangan teknologi di dunia industri berpengaruh terhadap muatan kurikulum sekolah menengah kejuruan. Sehingga kurikulum SMK disusun sedemikian rupa sehingga dapat menyesuaikan dengan kebutuhan di dunia kerja dan dunia industri. Salah satunya adalah jurusan Multimedia yang diharapkan bisa mencetak lulusan yang bisa siap kerja dalam hal Multimedia.

Mata pelajaran Dasar Desain Grafis merupakan salah satu mata pelajaran di SMK, khususnya sekolah menengah kejuruan bidang Multimedia, mata pelajaran dasar desain grafis diberikan pada siswa kelas X dan XI. Dalam jurusan Multimedia terdapat beberapa mata pelajaran diantaranya Simulasi dan Komunikasi Digital, Komputer dan
Jaringan Dasar, Pemrograman Dasar, Desain Grafis, Desain Grafis Percetakan, Teknik Animasi 2D dan 3D. Seseorang yang berkecimpung dalam bidang Multimedia harus dapat mengolah, mendesain dan membuat program karena hal tersebut merupakan keterampilan yang harus dimiliki. Oleh sebab itu dalam bidang Multimedia sangat penting untuk menguasai dasar desain grafis.

Proses pembelajaran yang hanya menggunakan buku dan internet membuat siswa merasa bosan dan tidak tertarik dengan mata pelajaran dasar desain grafis karena pelajaran tersebut terkesan monoton dan belum ada perubahan. Dalam pembelajaran siswa membutuhkan suasana menyenangkan yang dapat diciptakan melalui media dan metode yang bervariasi agar siswa tidak merasa bosan dan tertarik dalam proses pembelajaran.

Dari hasil observasi di SMK Islam Al - Amin dan latar belakang di atas, Maka peneliti membuat judul "Pengembangan Media Pembelajaran Interaktif Berbasis Adobe Flash Cs 6 Pada Mata Pelajaran Dasar Desain Grafis Kelas X Multimedia Smk Islam Al Amin Bonang Demak".

\section{METODE PENELITIAN}

Pengembangan ini menggunakan jenis pengembangan Research and Davelopment (R\&D). Penelitian ini mengambil model dari Hannafin dan Peck Karena menurut peneliti model ini berorientasi produk pembelajaran. Selain itu model ini merupakan model desain pembelajaran yang penyajiannya dilakukan secara sederhana namun elegan sehingga tidak memerlukan waktu lama pendapat Tegeh (2014: 1).

\section{Waktu dan Tempat Penelitian}

Tempat dan waktu dilaksanakan disekolah SMK Islam Al Amin Demak kelas $\mathrm{X}$ jurusan multimedia yang berjumlah 20 siswa. pengambilan 
sampel oleh guru Multimedia yang bersangkutan serta petimbangan efisien waktu oleh peneliti. Sampel dipilih langsung oleh guru mata pelajaran dasar desain atas dasar rata-rata hasil belajar dan kemampuan siswa.

\section{Prosedur}

(1)Analisis Kebutuhan, bertujuan untuk mengetahui sasaran yang akan dituju, pengetahuan, target pembuatan media pembelajaran, kecakapan peserta didik, dan alat yang dibutuhkan. Sesudah melakukan analisis kebutuhan, maka selanjutnya penilaian atau evaluasi produk yang dikembangkan, (2) Desain, proses dilakukan untuk mengetahui target dan mendokumentasi agar dapat menjadi petunjuk untuk pembuatan media pembelajaran yang interaktif yang sesuai harapan. Format yang dihasilkan dari proses desain ini adalah dokumentasi storyboard. Storyboard dibuat untuk memperoleh keperluan yang dibutuhkan oleh siswa dalam pembuatan media pembelajaran yang interaktif. Sesudah melakukan desain, maka selanjutnya mengevaluasi dan revisi.(3) Pengembangan dan Implementasi, tahap terakhir dalam penelitian ini, Menghasilkan diagram alur, melakukan pengujian, melakukan penilaian. Sebagai landasan untuk pembuatan diagram alur yaitu dari dokumen storyboard serta membantu proses penciptaan media pembelajaran. Penilaian pada proses ini digunakan untuk menilai lancarnya media yang dihasilkan, kemudian penyesuaian dilakukan berdasarkan hasil pengujian yang diperoleh guna mencapai kualitas media.

\section{Metode Pengumpulan Data}

Penelitian ini menggunakan instrumen penelitian berupa angket atau kuesioner. Kuesioner adalah metode pengumpulan data yang memberikan beberapa pernyataan atau pertanyaan tertulis kepada responden untuk di jawabnya (Sugiyono, 2011:216). Angket tersebut akan diberikan kepada ahli media, ahli materi dan pengguna atau siswa.

\section{Teknik Analisis Data}

Teknik analisis data pada penelitian ini adalah teknik analisis deskriptif. Penelitian ini dilakukan untuk menguji tingkat kelayakan produk bukan untuk menguji hipotesis. Produk diuji menggunakan angket penilaian kelayakan dengan Skala Likert. Skala Likert digunakan untuk mengembangkan instrumen yang digunakan untuk mengukur sikap, persepsi, dan pendapat seseorang (Sugiyono, 2015: 165). Data dikonversikan menjadi 5 skala. Setiap aspek yang akan untuk mengukur media diberi skor skala 1-5, yaitu (1) sangat tidak setuju, (2) tidak setuju, (3) raguragu, (4) setuju, (5) sangat setuju.

Analisis data dilakukan dengan data hasil angket yang berupa data kuantitatif. Data tersebut digunakan untuk menilai seberapa besar kelayakan media yang dibuat ketika di implementasikan pada materi dasar desain grafis

\section{HASIL DAN PEMBAHASAN}

(1) Analisis kebutuhan

Analisis kebutuhan dilakukan selama kegiatan observasi di SMK Islam Al amin, tahapan ini diawali dengan pengamatan dan observasi pada kelas X Multimedia. Selain itu proses analisis kebutuhan juga dilakukan melalui diskusi dengan guru mata pelajaran dasar desain grafis yang menghasilkan bahwa mata pelajaran dasar desain grafis membutuhkan media pembelajaran tambahan yang interaktif di kelas X SMK Islam Al amin.

(2) Desain

Proses ini peneliti membuat storyboard atau rancangan pembelajaran beserta keterangan- 
keterangan sebelum pembuatan media pembelajaran. Setelah storyboard telah selesai disusun, peneliti mulai menyusun bahan-bahan yang akan digunakan tahap pengembangan.

(3) Pengembangan dan Implementasi

Hasil dari pengembangan dan implementasi yaitu berupa diagram alir, pengujian media, serta penilaian. Diagram alir dibuat berdasarkan dari storyboard yang sudah dibuat sebelumnya.

\section{Hasil Uji Validitas}

1. Ahli Media

Tabel 1. Hasil validitas ahli media

\begin{tabular}{lcc}
\hline \multicolumn{1}{c}{$\begin{array}{c}\text { Aspek } \\
\text { Penilaian }\end{array}$} & $\begin{array}{c}\text { Responden } \\
\text { Ahli Media }\end{array}$ & $\begin{array}{c}\text { Skor } \\
\text { Maksimal }\end{array}$ \\
\hline $\begin{array}{l}\text { Informasi } \\
\text { Bantuan } \\
\text { Kualitas } \\
\text { Tampilan }\end{array}$ & 8 & 20 \\
$\begin{array}{l}\text { Kualitas } \\
\text { Teknis }\end{array}$ & 29 & 40 \\
Kemanfaatan & 32 & 30 \\
$\begin{array}{l}\text { Total Skor } \\
\text { Persentase }\end{array}$ & 0 & 10 \\
$\begin{array}{l}\text { Skor } \\
\text { Kategori }\end{array}$ & $69 \%$ & 100 \\
\hline
\end{tabular}

Persentase tersebut diperoleh dari tingkat kelayakan. Persentase ahli media diperoleh sebesar 69\% skor persentase tersebut diinterprestasikan menggunakan Sehingga dapat ditarik kesimpulan bahwa persentase ahli media masuk interval $69 \%$ - $84 \%$ dikategorikan "Layak".

\section{Ahli Materi}

Tabel 2. Hasil validitas ahli materi

\begin{tabular}{lcc}
\hline \multicolumn{1}{c}{$\begin{array}{c}\text { Aspek } \\
\text { Penilaian }\end{array}$} & $\begin{array}{c}\text { Responden } \\
\text { Ahli Materi }\end{array}$ & $\begin{array}{c}\text { Skor } \\
\text { maksimal }\end{array}$ \\
\hline $\begin{array}{l}\text { Kualitas Isi } \\
\text { dan Tujuan }\end{array}$ & 84 & 90 \\
$\begin{array}{l}\text { Kemanfaatan } \\
\text { Total Skor }\end{array}$ & 20 & 20 \\
$\begin{array}{l}\text { Presentase } \\
\text { Kategori }\end{array}$ & $\begin{array}{c}104 \\
\text { Sangat Layak }\end{array}$ & 110 \\
\hline
\end{tabular}

Persentase ahli materi sebesar 94,5 $\%$. Sehingga dapat ditarik kesimpulan bahwa presentase ahli materi masuk di interval $84 \%$ - $100 \%$ dikategorikan "Sangat Layak".

\section{Pengguna atau siswa}

Tabel 3. Hasil validitas pengguna atau siswa

\begin{tabular}{lllll}
\hline Aspek & Total & Rata & Skor & Perse \\
Penilaian & Skor & Skor & Max. & ntase \\
\hline $\begin{array}{l}\text { Informasi } \\
\text { bantuan }\end{array}$ & 178 & 8,9 & 10 & $89 \%$ \\
$\begin{array}{l}\text { Kualitas } \\
\text { isi dan } \\
\text { tujuan }\end{array}$ & 1001 & 50,05 & 55 & $91 \%$ \\
$\begin{array}{l}\text { Kualitas } \\
\text { tampilan }\end{array}$ & 368 & 18,4 & 20 & $92 \%$ \\
$\begin{array}{l}\text { Kualitas } \\
\text { Teknis }\end{array}$ & 279 & 13,95 & 15 & $93 \%$ \\
$\begin{array}{l}\text { Kemanfa } \\
\text { atan }\end{array}$ & 330 & 16,7 & 20 & 83,5 \\
Kategori & Sangat Layak & & \\
\hline
\end{tabular}

4. Uji Reliabilitas

Istilah reliabilitas instrumen mempunyai beberapa nama lain seperti konsistensi, keandalan, keterpercayaan, kestabilan, keejaan menurut (Azwar, 2018:7). Reliabilitas sebagai suatu pengujian untuk menunjukkan sejauh mana hasil suatu pengukuran dapat dipercaya. Ada beberapa macam formula untuk mencari koefisien reliabilitas yang disesuaikan dalam bentuk skor, jumlah belahan item,dan asumsi belahan pararel. Salah satu formula yang dapat digunakan untuk mengukur reliabilitas instrumen adalah formula Alpha Cronbach dengan bantuan aplikasi SPSS.

Tabel 4. Case Processing Summary

\begin{tabular}{cccc}
\hline & & $\mathrm{N}$ & $\%$ \\
\hline Cases & Valid & 20 & 100,0 \\
& Excluded $^{\mathrm{a}}$ & 0 & 0,0 \\
& Total & 20 & 100,0 \\
\hline
\end{tabular}


Tabel 5. Reliability Statistics

\begin{tabular}{cc}
\hline Cronbach's Alpha & N of Items \\
\hline, 739 & 24 \\
\hline
\end{tabular}

Tabel 5. Item-Total Statistics

\begin{tabular}{|c|c|c|c|c|}
\hline & $\begin{array}{l}\text { Scale } \\
\text { Mean if } \\
\text { Item } \\
\text { Deleted }\end{array}$ & $\begin{array}{c}\text { Scale } \\
\text { Varianc } \\
\text { e if } \\
\text { Item } \\
\text { Deleted }\end{array}$ & $\begin{array}{c}\text { Corrected } \\
\text { Item-Total } \\
\text { Correlatio } \\
n\end{array}$ & $\begin{array}{c}\text { Cronb } \\
\text { ach's } \\
\text { Alpha } \\
\text { if Item } \\
\text { Delete } \\
\text { d }\end{array}$ \\
\hline $\begin{array}{l}\text { butir } \\
1\end{array}$ & 103,3500 & 19,818 & ,466 &, 715 \\
\hline $\begin{array}{l}\text { butir } \\
2\end{array}$ & 103,3500 & 19,713 & ,487 &, 713 \\
\hline $\begin{array}{l}\text { butir } \\
3\end{array}$ & 103,3500 & 19,818 & ,466 &, 715 \\
\hline $\begin{array}{l}\text { butir } \\
4\end{array}$ & 103,3000 & 21,274 & ,245 & ,733 \\
\hline $\begin{array}{l}\text { butir } \\
5\end{array}$ & 103,4500 & 20,892 & ,272 &, 731 \\
\hline $\begin{array}{l}\text { butir } \\
6\end{array}$ & 103,2000 & 20,484 & ,430 &, 720 \\
\hline $\begin{array}{l}\text { butir } \\
7\end{array}$ & 103,3000 & 20,958 & ,314 & ,728 \\
\hline $\begin{array}{l}\text { butir } \\
8\end{array}$ & 103,3000 & 21,063 & ,291 &, 730 \\
\hline $\begin{array}{l}\text { butir } \\
9\end{array}$ & 103,2500 & 20,724 & ,292 &, 730 \\
\hline $\begin{array}{l}\text { butir } \\
10\end{array}$ & 103,2500 & 21,039 & ,298 & ,729 \\
\hline $\begin{array}{l}\text { butir } \\
11\end{array}$ & 103,1000 & 20,937 & ,274 & ,731 \\
\hline $\begin{array}{l}\text { butir } \\
12\end{array}$ & 103,1000 & 21,463 & ,232 &, 733 \\
\hline $\begin{array}{l}\text { butir } \\
13\end{array}$ & 103,1500 & 20,976 &, 330 & ,727 \\
\hline $\begin{array}{l}\text { butir } \\
14\end{array}$ & 103,0500 & 20,997 & ,368 &, 725 \\
\hline $\begin{array}{l}\text { butir } \\
15\end{array}$ & 103,2500 & 20,934 &, 321 & ,728 \\
\hline $\begin{array}{l}\text { butir } \\
16\end{array}$ & 103,3000 & 20,958 &, 314 & ,728 \\
\hline $\begin{array}{l}\text { butir } \\
17\end{array}$ & 103,2000 & 19,958 & ,445 &, 717 \\
\hline $\begin{array}{l}\text { butir } \\
18\end{array}$ & 103,1000 & 21,042 &, 332 &, 727 \\
\hline $\begin{array}{l}\text { butir } \\
19\end{array}$ & 103,1500 & 22,029 & ,093 & ,742 \\
\hline $\begin{array}{l}\text { butir } \\
20\end{array}$ & 103,2000 & 20,274 & ,479 &, 717 \\
\hline $\begin{array}{l}\text { butir } \\
21\end{array}$ & 103,5000 & 21,947 &, 119 &, 740 \\
\hline $\begin{array}{l}\text { butir } \\
22\end{array}$ & 103,7000 & 23,379 &,- 185 &, 763 \\
\hline $\begin{array}{l}\text { butir } \\
23\end{array}$ & 103,8000 & 22,484 &, 034 & ,742 \\
\hline $\begin{array}{l}\text { butir } \\
24\end{array}$ & 103,7000 & 22,747 &,- 068 &, 755 \\
\hline
\end{tabular}

Pengolahan data uji reliabilitas menggunakan rumus Alpha Cronbach dengan menggunakan bantuan software SPSS. Hasil mendapat nilai reliabilitas sebesar 0,739 dengan kategori "Cukup Layak".

\section{PENUTUP}

(1)Pengembangan media pembelajaran interaktif dapat menambah media dalam pembelajaran mata pelajaran dasar desain grafis selain buku dan internet tetapi juga berisi gambar, audio, video, teks, kuis yang lebih interaktif yang bisa lebih menarik siswa dalam belajar.

(2)Media interaktif di mata pelajaran dasar desain grafis ini berisi materimateri yang bisa dipelajari siswa dan atau dipelajari dengan guru supaya siswa tidak merasa bosan dalam belajar mata pelajaran dasar desain grafis serta dapat memperjelas pemahaman siswa terhadap materi dasar desain grafis.

(3)Hasil kelayakan aplikasi yang dibuat dengan materi dasar desain grafis memperoleh hasil "Sangat Layak" dengan skor ahli materi sebesar 94,5\%, ahli media sebesar $69 \%$, dan dari pengguna sebesar $90 \%$. Hal ini dapat ditarik kesimpulan bahwa media ini dapat digunakan dalam proses pembelajaran di SMK Islam Al amin Bonang Demak di mata pelajaran dasar desain grafis.

\section{DAFTAR PUSTAKA}

Azwar, Saifuddin. (2018). Reliabilitas dan Validitas. Yogyakarta: Pustaka Belajar

I Made Tegeh, I Nyoman Jampel, dan Ketut Pudjawan. (2014). Model Penelitian Pengembangan, Yogyakarta: Graha Ilmu.

Sugiyono. (2011). Metode Penelitian Pendidikan. Bandung: Alfa Beta.

Sugiyono. (2015). Statistika untuk penelitian. Bandung: Alfa Beta. 
